\title{
The analysis of the impact of bone cement leakage through the endplate on the prognosis of patients after PKP on intervertebral disc
}

\section{Zhong-lai Qian ( $\sim$ qzldoctor@163.com )}

First Affiliated Hospital of Soochow University

\section{Xi Hua}

First Affiliated Hospital of Soochow University

Nan-ning Lv

Lianyungang Second People's Hospital

Lei Deng

First Affiliated Hospital of Soochow University

Jun-Xin Zhang

First Affiliated Hospital of Soochow University

\section{Research Article}

Keywords: Bone cement leakage, osteoporotic vertebral compression fracture, Percutaneous kyphoplasty, Intervertebral disc, End plate

Posted Date: February 24th, 2022

DOI: https://doi.org/10.21203/rs.3.rs-1334700/v1

License: (c) (1) This work is licensed under a Creative Commons Attribution 4.0 International License. Read Full License 


\section{Abstract}

Background:There is a high incidence in the elderly who come down with osteoporotic vertebral compression fracture (OVCF) and percutaneous kyphoplasty (PKP) is an effective solution which can relieve pain quickly. Previous studies have shown that both the volume and the distribution of bone cement filling are related to the clinical outcome after PKP surgery. However, the influence of bone cement leakage through the endplate after PKP on intervertebral disc remains to be explained.

Methods:118 patients with single level OVCF operated by PKP were retrospectively reviewed from 2015 to 2020. These patients were grouped according to the degree of bone cement leakage. Group A: Bone cement leakage involving one endplate relative to the intervertebral disc. Group B: Bone cement leakage involving one endplate and the adjacent disc. Group C: Bone cement leakage involving both endplates of the intervertebral disc. The following variables were reviewed: gender, age, BMI, BMD and surgical parameters including cement volume (CV), Oswestry Disability Index (ODI), Visual analogue Scale (VAS), Anterior vertebral height ration (AVHR), Local kyphotic angle (LKA), Intervertebral space height (ISH) and the incidence of complications.

Results:Compared with the preoperative for all groups, the VAS, ODI, AVHR, LKA and ISH were improved significantly after PKP. There is no significant difference among groups in AVHR and LKA $(P>0.05)$. Compared with preoperative levels, there was a significant reduction in fracture perivertebral pain in all groups after the surgery, but at the last follow-up, the VAS of Group $\mathrm{C}$ were worser than other groups (3.28 \pm 0.29 vs. $2.55 \pm 0.67 v$ v. $1.73 \pm 0.51, P<0.05)$ and the ODI of Group $C$ were also worser than other groups ( $44.46 \pm 6.65$ vs. $35.77 \pm 6.33$ vs. $29.80 \pm 5.96, \mathrm{P}<0.05$ ). At the last follow-up, the ISH of group C was worser than group $B$ and group $C(4.04 \pm 0.38$ vs. $4.63 \pm 0.27$ vs. $5.19 \pm 0.34, P<0.05)$. The complications including the adjacent vertebral fracture (AVF) and backache of group $A$ was $(1 / 39,2.5 \%)$, that of group $B$ was $(6 / 33,15.4 \%)$ and that of group $C$ was $(17 / 22,42.5 \%)$. The incidence of complications in the group $C$ was significantly higher than that in the other groups $(P \otimes 0.05)$.

Conclusions:As the area of bone cement leaking from one endplate to another endplate of the intervertebral disc increases, there is no significant difference in the short-term effect after surgery, but the patient's long-term postoperative efficacy becomes worse. The incidence of AVF and back pain of adjacent vertebral bodies increases. It even aggravated the degeneration of the intervertebral disc and the symptoms of discogenic neuralgia appeared.

\section{Introduction}

Osteoporosis has become one of the important reasons for elderly patients and seriously influences the quality of life of patients. Osteoporosis is a systemic bone disease with reduced body bone mass which decreases bone trabecular density and increases bone fragility. As osteoporosis progresses, a vertebral fracture can be caused by a small amount of force. We call this disease osteoporotic vertebral compression fracture (OVCF). The main symptom of this disease is low back pain. Most patients with 
pain generally have no nerve root symptoms, but sometimes have abdominal or intercostal pain, especially when turning or moving which seriously affecting the patient's daily life [1].

Percutaneous kyphoplasty (PKP) that creates a cavity in the vertebral body with a balloon (inflatable bone tamp) before injecting polymethylmethacrylate (PMMA) bone cement, was first designed by Wong and Reiley and got approved by the FDA for clinical use in 1998. Liberman first reported the use of PKP in the clinic in 2001 [2]. Percutaneous balloon kyphoplasty (PKP) is an effective treatment for osteoporotic vertebral compression fractures because it effectively reconstructs the height of the vertebral body and relief pain [3-6]. In the ageing population, the minimally invasive technique significantly improves the patient's life expectancy, greatly reduces the fatal complications caused by the conservative treatment of OVCF patients in bed, makes the elderly patients immediately out of the bed after the operation. However, this type of surgery can also lead to pulmonary embolism, bone cement leakage, the adjacent vertebral fracture (AVF) and other complications [7, 8]. Bone cement leakage is one of its common complications. Usually, bone cement leakage into the paravertebral soft tissue or around the vertebrae will not produce clinical symptoms, but bone cement leakage into the spinal canal through the posterior wall may cause a series of neurological symptoms, or through the paravertebral vein system leakage may cause pulmonary embolism or even life-threatening. [9-11]

In recent years, the leakage of bone cement into adjacent intervertebral discs after percutaneous vertebral augmentation has gradually attracted the attention of some scholars. This is because infiltration of bone cement into the disc may increase the risk of AVF after surgery, and leakage of bone cement into the disc may have an impact on disc degeneration. We established a new classification of bone cement leakage based on the relationship between the position of bone cement and the position of the intervertebral disc, aiming to study the effect of bone cement leakage into the intervertebral disc through the end plate after PKP on postoperative pain relief and functional recovery of patients. We hope that our study can provide some guidance for clinical PKP surgery.

\section{Methods}

\section{General Information}

We retrospectively reviewed the patients who were diagnosed with single level OVCF between June 2015 and December 2020. All patients with OVCF underwent PKP surgery in our hospital. The inclusion criteria were as follows: 1) All patients and their families signed informed consent forms and approved by the medical ethics committee. 2) Osteoporotic thoracolumbar fracture was confirmed by imaging examination. 3) The follow-up time was more than 18 months and preoperative computed tomography (CT), magnetic resonance imaging (MRI) and postoperative x-rays were available. 4) Fracture of one single segment of the vertebral body. The exclusion criteria were as follows: 1) Pathologic vertebral lesions such as vertebral metastatic carcinoma, vertebral hemangioma and myeloma, etc. 2) There was previous disease related to back pain, such as lumbar muscle strain, disc herniation of the compression fracture segment and spinal stenosis.3) Patients who were lost to follow-up. All the cases we included in 
the retrospective study met the above criteria. All patients underwent preoperative X-ray, CT, and MRI. Identify the fractured vertebra as the responsible vertebra for pain. The preoperative and follow-up X-rays for each patient were complete and available.

According to the position of the bone cement on the postoperative radiographs, these patients were divided into group three groups (Fig. 1): Group A: Bone cement leakage involving one endplate relative to the disc. A 63-year-old woman was diagnosed with L1 OVCF after a collision with her lower back whose bone cement is defined as an A-pattern pattern (Fig. 2). Group B: Bone cement leakage involving one endplate and the adjacent disc. A 57-year-old woman was diagnosed with T12 OVCF due to a fall whose bone cement is defined as a B-pattern pattern (Fig. 3). Group C: Bone cement leakage involving both endplates of the intervertebral disc. A 71-year-old woman knocked down by a bicycle was diagnosed with L1 OVCF whose bone cement is defined as a C-pattern pattern (Fig. 4).

\section{Surgical Technique}

The operation is performed under general anesthesia. Standard anteroposterior and lateral images of the vertebral body were captured by C-arm X-ray. Firstly, the position of the injured vertebra was located and the projection point of the pedicle on the body surface of the injured vertebra was marked. Bilateral pedicle puncture approach was adopted to reach about $3 \mathrm{~mm}$ in front of the posterior edge of the vertebra. The guide wire, expansion cannula and working cannula were placed in sequence, and then the inflatable balloon was placed into the vertebral body through the working cannula and inflated under fluoroscopic guidance. The prepared polymethylmethacrylate cement was slowly inserted into the vertebral body through a cannula under fluoroscopic monitoring. The injection was stopped as the cement was closed as the posterior wall of the vertebra. Finally, the cannula was removed. The patients were allowed to walk 18 hours after surgery.

\section{Assessed Parameters}

Visual Analogue Scale (VAS) scores was used to assess patients' subjective pain perception before surgery, 1 day after surgery, 1 year after surgery, and at the last follow-up (0-10 scale, with 0 being painless and 10 being the most painful). In addition, the Oswestry Disability Index (ODI) score was used to assess improvements in quality of life before surgery, 1 day after surgery, 1 year after surgery, and at the last follow-up. The anterior vertebral height ratio (AVHR), local kyphosis angle (LKA) of the injured vertebra and intervertebral space height (ISH) were measured and calculated before surgery, one day after surgery, one year after surgery, and at the last follow-up, to assess the degree of reduction and correction. The AVHR was defined as the percentage of the anterior height of fractured vertebrae with respect to the mean value of anterior vertebral height of the vertebra above and below the injured level. The LKA was measured as the angle between the superior endplate of the vertebrae above and the inferior endplate of the vertebrae below the fractured level. ISH was measured by the average height of the intervertebral disc $(\mathrm{H} 1+\mathrm{H} 2) / 2$. These five indicators were used to assess clinical efficacy (Fig. 5).

\section{Statistical Methods}


SPSS 26.0 statistical software (SPSS Inc. Chicago, IL) was used for data analysis. The results were presented as means \pm standard deviations. The level of statistical significance was set at $p<0.05$. The subjects' ages, sex, BMD T socre, Follow-up months and BMI were compared and analyzed using analysis of variance (ANOVA). ANOVA was also used to compare the degree of VAS, ODI, AVHR, LKA and ISH at each stage. The paired T-test was used for within-group comparisons preoperatively, 1 day after surgery, and 1 year after surgery and the last follow up day.

\section{Results}

\section{Demograhics}

The demographic data of the three groups in shown in (Table 1). We analyzed 118 OVCF patients with the bone cement leakage who operated by bilateral pedicle approach in our hospital from June 2015 to October 2020. The mean age of these 118 patients was $71.85 \pm 9.94$ years (range,45 95) The mean follow-up time was $20.97 \pm 4.63$ months (range,18 26). According to the degree of bone cement leakage, these patients were divided into three groups. Group A: the mean age of 40 patients (14 male patients and 26 female patients) was $72.28 \pm 8.62$. The mean preoperative BMD was $-2.7 \pm 0.3$. Group B: the mean age of 39 patients ( 12 male patients and 27 female patients) was $73.28 \pm 11.52$. The mean preoperative BMD was $-2.75 \pm 0.39$. Group C: the mean age of 39 patients ( 13 male patients and 26 female patients) was $69.97 \pm 9.45$. The mean preoperative BMD was $2.84 \pm 0.46$. The mean BMI of groups are $(22.59 \pm 3.5$ vs. $22.98 \pm 3.51$ vs. $22.62 \pm 3.45, P>0.05)$ There were no significant differences among the three groups in the above indicators $(P>0.05$ Table 1$)$.

Table 1

Demographics of Groups

\begin{tabular}{|lllll|}
\hline & Group A(n= 40) & Group B(n=39) & Group C( $\mathbf{n = 3 9 )}$ & P-Value \\
\hline Age, years & $72.28 \pm 8.62$ & $73.28 \pm 11.52$ & $69.97 \pm 9.45$ & $.324 / \mathrm{NA}$ \\
\hline Sex, M/F & $14 / 26$ & $12 / 27$ & $13 / 26$ & $.494 / \mathrm{NA}$ \\
\hline BMD T score & $-2.70 \pm 0.30$ & $-2.75 \pm 0.39$ & $-2.84 \pm 0.46$ & $.253 / \mathrm{NA}$ \\
\hline Follow-up, months & $20.98 \pm 4.73$ & $21.05 \pm 4.61$ & $20.90 \pm 4.67$ & $.989 / \mathrm{NA}$ \\
\hline BMI & $22.59 \pm 3.5$ & $22.98 \pm 3.51$ & $22.62 \pm 3.25$ & $.853 / \mathrm{NA}$ \\
\hline by ANOVA test & & & & \\
NA: Not Applicable & & & & \\
\hline
\end{tabular}

\section{Clinical Efficacy Outcomes}

The clinical efficacy data were shown below. The ODI and VAS have significant differences after the surgery among groups. Notably, the ODI value of group A $(29.80 \pm 5.96)$ was better than that of group $B(32.77 \pm 6.33)$ and $C(34.46 \pm 6.65)$ at the last follow-up day (Pख0.05). The VAS value of group $A \bowtie 1.73 \pm$ 
0.51 『was better than that of group $B(2.15 \pm 0.67)$ and $C(2.28 \pm 0.69)$ at the last follow-up day (P凶0.05 Table 2). Compared the preoperative, the AVHR, LKA and ISH all improved significantly in all groups after the surgery (Pख0.05, Table 3). There were no significant differences in AVHR and LKA among groups after the surgery (Table 3 and Table 4). The ISH value of group $C(4.04 \pm 0.38)$ was worser than that of group $B$ $(4.63 \pm 0.27)$ and $A(5.19 \pm 0.34)$ at the last follow-up day (Pष0.05 Table 5).

Table 2

Clinical Efficacy outcomes for groups

\begin{tabular}{|c|c|c|c|c|}
\hline & Group A $(n=40)$ & Group B $(n=39)$ & Group C $(n=39)$ & $\begin{array}{l}\text { P-Value } \\
\text { Anova }\end{array}$ \\
\hline VAS & $7.88 \pm 1.11$ & $8.10 \pm 1.12$ & $8.46 \pm 0.68$ & .034 \\
\hline Preop & $2.08 \pm 0.86^{\star}$ & $2.13 \pm 0.80^{*}$ & $2.42 \pm 0.92^{\star}$ & .168 \\
\hline Postop 1d & $2.15 \pm 0.66^{*}$ & $2.23 \pm 0.71^{\star}$ & $2.69 \pm 0.80^{*}$ & .002 \\
\hline Postop 1y & $1.73 \pm 0.51^{*}$ & $2.55 \pm 0.67^{*}$ & $3.28 \pm 0.69 *$ & .000 \\
\hline Final & $83.88 \pm 2.36$ & $83.97 \pm 3.17$ & $84.72 \pm 6.44$ & .645 \\
\hline ODI & $32.45 \pm 6.90$ * & $34.03 \pm 3.52^{\star}$ & $36.77 \pm 6.71 *$ & .006 \\
\hline Preop & $30.20 \pm 6.17 *$ & $33.69 \pm 5.83^{*}$ & $38.37 \pm 6.52 *$ & .002 \\
\hline Postop 1d & $29.80 \pm 5.96^{*}$ & $35.77 \pm 6.33^{*}$ & $44.46 \pm 6.65^{\star}$ & .000 \\
\hline \multicolumn{5}{|l|}{ Postop 1y } \\
\hline \multicolumn{5}{|l|}{ Final } \\
\hline \multicolumn{5}{|c|}{$\begin{array}{l}\text { Preop, preoperation; Postop 1d, one day after operation; Postop 1y, one year after operation; Final, the } \\
\text { last follow-up. }\end{array}$} \\
\hline \multicolumn{5}{|c|}{ VAS, visual analogue scale; ODI, oswestry disability index. } \\
\hline \multicolumn{5}{|c|}{ * compared with preoperation, $P<0.05$. T test } \\
\hline Others by a & test & & & \\
\hline
\end{tabular}


Table 3

AVHR change in the three groups.

\begin{tabular}{|c|c|c|c|c|c|}
\hline \multirow[t]{2}{*}{ Group } & \multirow{2}{*}{$\begin{array}{l}\text { AVHR (\%) } \\
\text { preop }\end{array}$} & \multirow{2}{*}{$\begin{array}{l}\text { AVHR (\%) } \\
\text { Post1d }\end{array}$} & \multirow{2}{*}{$\begin{array}{l}\text { AVHR (\%) } \\
\text { Post1y }\end{array}$} & \multirow{2}{*}{$\begin{array}{l}\text { AVHR } \\
(\%) \\
\text { Final }\end{array}$} & \multirow{2}{*}{$\begin{array}{l}\text { P value } \\
\text { Perop vs.post } 1 d \text { / perop vs. } 1 \text { year/ } \\
\text { perop vs. Final }\end{array}$} \\
\hline & & & & & \\
\hline$A(40)$ & $\begin{array}{l}58.86 \pm \\
11.90\end{array}$ & $\begin{array}{l}82.72 \pm \\
10.43\end{array}$ & $\begin{array}{l}83.18 \pm \\
9.99\end{array}$ & $81.99 \pm 9.95$ & $0.000 / 0.000 / 0.000$ \\
\hline$B(39)$ & $\begin{array}{l}58.54 \pm \\
10.65\end{array}$ & $\begin{array}{l}87.56 \pm \\
7.53\end{array}$ & $\begin{array}{l}86.68 \pm \\
6.65\end{array}$ & $85.82 \pm 6.37$ & $0.000 / 0.000 / 0.000$ \\
\hline$C(39)$ & $\begin{array}{l}60.75 \pm \\
10.75\end{array}$ & $\begin{array}{l}84.20 \pm \\
8.49\end{array}$ & $\begin{array}{l}83.57 \pm \\
9.71\end{array}$ & $82.85 \pm 9.07$ & $0.000 / 0.000 / 0.000$ \\
\hline $\begin{array}{l}P \\
\text { value } \\
\star\end{array}$ & $.638 *$ & $.050 *$ & $.167 *$ & $.122^{\star}$ & \\
\hline \multicolumn{6}{|c|}{$\begin{array}{l}\text { Preop, preoperation; Postop 1d, one day after operation; Postop 1y, one year after operation; Final, the } \\
\text { last follow-up. }\end{array}$} \\
\hline \multicolumn{6}{|c|}{ AVHR, anterior vertebral height ratio. } \\
\hline \multicolumn{6}{|c|}{ *by ANOVA test } \\
\hline Others & y paired $\mathrm{T} t$ & & & & \\
\hline
\end{tabular}


Table 4

LKA change in the three groups.

\begin{tabular}{|c|c|c|c|c|c|}
\hline \multirow[t]{2}{*}{ Group } & $\operatorname{LKA}\left({ }^{\circ}\right)$ & $\operatorname{LKA}\left({ }^{\circ}\right)$ & $\operatorname{LKA}\left({ }^{\circ}\right)$ & $\operatorname{LKA}\left({ }^{\circ}\right)$ & $P$ value \\
\hline & preop & Post1d & Post1y & Final & $\begin{array}{l}\text { Perop vs.post1d/ perop vs. } 1 \text { year/ } \\
\text { perop vs. Final }\end{array}$ \\
\hline$A(40)$ & $\begin{array}{l}27.20 \pm \\
1.54\end{array}$ & $\begin{array}{l}14.90 \pm \\
1.64\end{array}$ & $\begin{array}{l}15.47 \pm \\
0.94\end{array}$ & $15.41 \pm 1.06$ & $0.000 / 0.000 / 0.000$ \\
\hline$B(39)$ & $\begin{array}{l}27.47 \pm \\
2.72\end{array}$ & $\begin{array}{l}14.04 \pm \\
1.72\end{array}$ & $\begin{array}{l}15.28 \pm \\
1.14\end{array}$ & $15.23 \pm 1.18$ & $0.000 / 0.000 / 0.000$ \\
\hline$C(39)$ & $\begin{array}{l}27.54 \pm \\
3.25\end{array}$ & $\begin{array}{l}13.98 \pm \\
1.04\end{array}$ & $\begin{array}{l}15.27 \pm \\
1.19\end{array}$ & $15.12 \pm 1.12$ & $0.000 / 0.000 / 0.000$ \\
\hline $\begin{array}{l}P \\
\text { value } \\
\star\end{array}$ & $.823^{\star}$ & $.110 *$ & $.664^{\star}$ & $.516^{*}$ & \\
\hline \multicolumn{6}{|c|}{$\begin{array}{l}\text { Preop, preoperation; Postop 1d, one day after operation; Postop 1y, one year after operation; Final, the } \\
\text { last follow-up. }\end{array}$} \\
\hline \multicolumn{6}{|c|}{ LKA, local kyphosis angle. } \\
\hline \multicolumn{6}{|c|}{ *by ANOVA test } \\
\hline \multicolumn{6}{|c|}{ Others by paired $\mathrm{T}$ test } \\
\hline
\end{tabular}


Table 5

ISH change in the three groups.

\begin{tabular}{|c|c|c|c|c|c|}
\hline \multirow[t]{2}{*}{ Group } & ISH(mm) & ISH(mm) & ISH(mm) & ISH(mm) & $P$ value \\
\hline & preop & Post1d & Post1y & Final & $\begin{array}{l}\text { Perop vs.post1d/ perop vs. } 1 \text { year/ } \\
\text { perop vs. Final }\end{array}$ \\
\hline$A(40)$ & $\begin{array}{l}6.68 \pm \\
0.68\end{array}$ & $\begin{array}{l}6.45 \pm \\
0.44\end{array}$ & $\begin{array}{l}5.95 \pm \\
0.56\end{array}$ & $5.19 \pm 0.34$ & $0.368 / 0.000 / 0.000$ \\
\hline$B(39)$ & $\begin{array}{l}6.65 \pm \\
0.73\end{array}$ & $\begin{array}{l}6.29 \pm \\
0.52\end{array}$ & $\begin{array}{l}5.30 \pm \\
0.67\end{array}$ & $4.63 \pm 0.27$ & $0.000 / 0.000 / 0.000$ \\
\hline$C(39)$ & $\begin{array}{l}6.57 \pm \\
0.70\end{array}$ & $\begin{array}{l}5.83 \pm \\
0.59\end{array}$ & $\begin{array}{l}4.78 \pm \\
0.61\end{array}$ & $4.04 \pm 0.38$ & $0.000 / 0.000 / 0.000$ \\
\hline $\begin{array}{l}P \\
\text { value } \\
\star\end{array}$ & $.731^{\star}$ & $.000 *$ & $.000 *$ & $.000 *$ & \\
\hline \multicolumn{6}{|c|}{$\begin{array}{l}\text { Preop, preoperation; Postop 1d, one day after operation; Postop 1y, one year after operation; Final, the } \\
\text { last follow-up. }\end{array}$} \\
\hline \multicolumn{6}{|c|}{ ISH, Intervertebral space height. } \\
\hline \multicolumn{6}{|c|}{ *by ANOVA test } \\
\hline \multicolumn{6}{|c|}{ Others by paired $\mathrm{T}$ test } \\
\hline
\end{tabular}

\section{Operation related Indicators and complications.}

There were no significant differences in operation time and hospital stay among groups. However the cement volume, time out of bed and complications have huge differences among groups. The CV (cement volume) value of group C $(7.87 \pm 1.47)$ was more than that of group B $(7.33 \pm 1.58)$ and $A(6.64 \pm$ $1.44, P \llbracket 0.05)$. The incidence of complications of group $C(17 / 39,2.5 \%)$ was more than that of group $B$ $(6 / 33,15.4 \%)$ and $A(1 / 39, P \llbracket 0.05,42 . \%)$. (Table 6) 1 case of AVF occurred in group A;There were 3 cases of AVF and 3 cases of low back pain symptoms in group B. In Group C there were 6 cases of AVF and 11 cases of low back pain symptoms. 
Table 6

Operation related Indicators and complications for Groups

\begin{tabular}{|lllll|}
\hline & Group A(n= 40) & Group B( $\mathbf{n = 3 9 )}$ & Group C( $\mathbf{n = 3 9 )}$ & Value \\
\hline OT (min) & $49.62 \pm 17.76$ & $55.54 \pm 21.07$ & $58.97 \pm 48.33$ & .431 \\
\hline CV $(\mathrm{ml})$ & $6.64 \pm 1.44$ & $7.33 \pm 1.58$ & $7.87 \pm 1.47$ & .002 \\
\hline TOB, (h) & $2.17 \pm 0.55$ & $3.31 \pm 0.86$ & $4.64 \pm 1.41$ & .000 \\
\hline HS (day) & $6.88 \pm 3.41$ & $8.10 \pm 4.61$ & $7.59 \pm 2.43$ & .316 \\
Complication Y/N & $1 / 39$ & $6 / 33$ & $17 / 22$ & .000 \\
\hline $\begin{array}{l}\text { OT, operation time; CV, cement volume; TOB, time out of bed; HS, hospital stay; Complication, } \\
\text { recurrent low back pain or new re-fractures. }\end{array}$ \\
\hline
\end{tabular}

\section{Discussion}

Osteoporotic vertebral compression fracture is a common spinal injury which the elderly patients are more likely to get the disease, PKP has a significant effect of small trauma and rapid pain relief and has now become an important method for the treatment of OVCF [12]. These days with the advancement of technology and the skilled operation of doctors, the leakage rate of bone cement is getting less and less, but it is inevitable. Once the bone cement leaks, the bone cement leakage around the vertebral body can stimulate the sympathetic nerves, the leakage in the spinal canal can compress the nerves, the intervertebral disc leakage can accelerate the degeneration of the intervertebral disc in the adjacent vertebral body segments, and the leakage of bone cement into the lungs may be life-threatening. Although more and more studies have been done on bone cement leakage, little has been said about endplate and disc leakage.

Previously, some scholars who mainly study the influence of the classification of bone cement leakage on the treatment effect [13-16]. However, we can see that the classification criteria used in different studies are not the same and the conclusions are still unable to reach a consensus accounting for the bone cement leaking into the intervertebral space has different anatomical distributions and its different dosages, directions, solidification.

In this paper, a new classification based on the nutritional relationship between the intervertebral disc and the upper and lower endplates was developed to explore the impact of bone cement leakage on patient outcomes and intervertebral discs. Adequate bone cement contact with the unilateral endplate can provide good immediate analgesia, but there may be no specific discomfort in the short term once leakage occurs. However, under the action of long-term leakage, bone cement may play a certain role in the degeneration of the intervertebral disc [17]. On the one hand, the force of the vertebral body is uneven, and on the other hand, the nutrient supply relationship between the bilateral endplates to the intervertebral disc is broken. 
In our study, we can see that the CV of Group C is more than other groups. In a sense, the increase in the amount of bone cement leads to the severity of leakage. There is intense debate about the optimal injection volume of bone cement. The main function of bone cement is to restore the stiffness and strength of the vertebrae, and the risk of bone cement leakage increases as the amount of bone cement increases. Most scholars pointed out that only $2 \mathrm{ml}$ of bone cement can restore the strength of the vertebral body, but more bone cement can restore the stiffness of the vertebral body. Studies have also shown that $15 \%$ bone cement filling rate in the vertebral body can restore the stiffness of the vertebral body, and when the bone cement volume fraction reaches $24 \%$ or higher, bone cement leakage or new fractures will occur $[18,19]$. According to the leakage, we can explore the effect of bone cement leakage to the upper and lower endplates of the intervertebral disc on the prognosis of patients to some degree.

The main components of the vertebral body endplates are proteoglycan, collagen and water, which are consistent with the composition of the intervertebral disc. These nutrients enter the intervertebral disc through passive diffusion. The endplate of the vertebral body plays an important role in nourishing the intervertebral disc and transferring stress. The endplate has a significant influence on the normal physiological state and pathological changes of the lumbar intervertebral disc. Injury and degenerative changes of the vertebral body endplates can significantly affect the biomechanics and nutrient supply status of the intervertebral disc, which in turn leads to degeneration of the lumbar spine [20-22]. When bone cement leaks into the bilateral end plates of the disc, it inevitably accelerates disc degeneration and instability. There was no difference among groups in short-term postoperative VAS when bone cement penetrated into the disc and bilateral endplates. However, with bilateral endplate involvement after longterm operation, VAS and ODI at the last follow-up were significantly worse than the other two groups. It can be seen from this that intervertebral disc nutrition can change due to leakage of bone cement into the intervertebral disc or bilateral endplates, which can cause dysfunction of intervertebral disc cells and even death of intervertebral disc cells. The dehydration of the intervertebral disc loses its normal elasticity and tension, which accelerates the degeneration of the intervertebral disc. On this basis, the annulus fibrosus is weakened or ruptured due to severe trauma or repeated indistinct injuries, and the nucleus pulposus is prolapsed from there, compressing the nerve root, resulting in signs of nerve root compression. This may also be the reason why patients with bone cement leaking into the bilateral endplates have recurrent intractable low back pain. Therefore, the effect of simple leakage of one endplate of the intervertebral disc and the simultaneous involvement of both endplates on the intervertebral disc and the postoperative curative effect are worthy of our study.

In our study, regardless of the type of cement distribution, there was a clear benefit for short-term pain relief and restoration of vertebral height. This may be because there is another endplate that provides nutrition and water to the intervertebral disc and this is consistent with previous clinical experience. However, at long-term follow-up, pain in group $\mathrm{C}$ was significantly higher than in the other two groups. When bone cement leaks to the other endplate, recompression of the vertebral body on the one hand may lead to spinal balance, local kyphosis, and thus chronic pain [23,24]. However, our study found no significant difference in AVHR and LKA among the groups, only statistically significant relative to preoperative. On the other hand, the nutritional supply of the intervertebral disc is unbalanced, which 
accelerates the degeneration and may cause discogenic neuralgia. In addition, when the vertebral body endplate is fractured, if the connection between the bone cement and the endplate is not good, it will provide insufficient support, resulting in vertebral body fracture. The fractured vertebral body is continuously compressed, which is why the pain persists after surgery.

There are different opinions on the causes of AVF after surgery. It is still controversial for the reasons for re-fractures such as the natural development of osteoporosis, biomechanical changes and excessive injection of bone cement and the leakage of bone cement into the intervertebral disc. However, with the indepth study of the OVCFs, many scholars have found that recurring vertebral fractures after PKP. They are mostly in the adjacent segment vertebral body and the incidence is relatively high. At present, most scholars believe that low BMD, fracture surface and the number of the vertebral body, amount of bone cement, the degree of leakage of bone cement intervertebral space and the compression of fracture vertebral body, postoperative height recovery, ISH, etc. They all may be related to recurrence of vertebral fractures after PKP.

Compared with the previous two groups, the disc height of the $\mathrm{C}$ group was lower, which is similar to the previous study [25], and at the last follow-up, the disc height of the cemented disc leakage group was significantly reduced compared with the disc height of the non-leakage group, indicating that bone cement intervertebral disc leakage will accelerate the progress of intervertebral disc degeneration to compress the height of dis. However, the mechanism by which the leakage of bone cement aggravates the degeneration of the intervertebral disc is still unclear. It has been noted in previous studies that bone cement leakage into the disc increases pressure on the disc and accelerates disc degeneration procedures $[26,27]$. When the leakage of the upper and lower endplates of the same intervertebral disc is involved at the same time, whether it is the force on the intervertebral disc or the nutritional supply of the intervertebral disc, the degeneration of the intervertebral disc is promoted to a certain extent [28, 29]. This may also be why AVF and recurrent low back pain are more likely to occur. To explore the relationship between intervertebral disc degeneration and AVF caused by bone cement leakage to the intervertebral disc and endplate, more researches are needed on bone cement leakage into the intervertebral discs and endplates in the future.

\section{Limitations}

Because this study is a retrospective study, and due to the limitations of the small sample size, it still needs to be further explored in the later stage of prospective wins, large samples, and multiple randomized controlled studies. The best indicator of intervertebral disc degeneration is not the height of the intervertebral disc in X-ray examination, but MRI scan. Because X-ray examination has the advantages of low price and fast imaging compared with MRI examination, X-ray examination is often selected for regular review after PKP not MRI scans. All indicators are measured manually and there are certain measurement errors. In addition, there may be some deviations in the frontal and lateral projection 
angles of the spine taken at various time points after surgery and the resulting measurement errors are also included in this study.

\section{Conclusion}

Unilateral endplate leakage after PKP operation will not have much impact on the patient's prognosis, but once it leaks to the intervertebral disc, or even the endplate on the other side of the intervertebral disc, it will greatly compress the ISH and affect patient's prognosis. Maybe that's why appear AVF, low back pain and discogenic neuralgia in long-term. Further research is needed on bone cement leakage into the discs and endplates.

\section{Abbreviations}

OVCF: Osteoporotic Vertebral compression Fracture,

PKP: Percutaneous Kyphoplasty,

VAS: Visual analogue Scale,

ODI: Oswestry Disability Index,

AVHR: Anterior vertebral height ratio,

LKA: Local kyphotic angle,

ISH囚Intervertebral space height,

AVF囚adjacent vertebral fracture.

\section{Declarations}

\section{Ethics approval and Consent to participate:}

Approval was obtained from the ethics committee of Soochow University. The procedures used in this study adhere to the tenets of the Declaration of Helsinki. Informed consent was obtained from all individual participants included in this study.

\section{Consent for publication:}

Not applicable.

\section{Availability of data and material statements $\llbracket$}


Data is available via a request to the corresponding author.

\section{Conflicts of Interest:}

All authors declare that they have no conflict of interest.

\section{Funding:}

This work was supported by the Lianyungang Health Science and Technology Project (No. 201917), and the Growth Foundation for middle-aged and young medical talents of The Second People's Hospital of Lianyungang (No. TQ202002), and the major scientific and technological projects of Bengbu Medical College (No. 2020byzd339), and the Lianyungang aging health research project (No. L202116).

\section{Authors' contributions:}

Xi Hua: Conceptualization, Methodology, Investigation, Software, Writing - original draft.

Lei Deng: Methodology, Data curation, Investigation, Writing - original draft.

Zhong-lai Qian: Conceptualization, Methodology, Data curation, Validation, Writing - review \& editing.

Nan-Ning Lv: Conceptualization, Methodology, Data curation, Validation, Writing - review \& editing, Funding acquisition.

Jun-Xin Zhang: Data curation, Validation, Writing - review \& editing.

\section{Acknowledgements:}

Thank you for all the support from the First Affiliated Hospital of Soochow University.

\section{References}

1. Cooper, C., E.J. Atkinson, W.M. O'Fallon, and L.J. Melton, 3rd, Incidence of clinically diagnosed vertebral fractures: a population-based study in Rochester, Minnesota, 1985-1989. J Bone Miner Res, 1992. 7(2): p. 221-7.

2. Garfin, S.R. and M.A. Reilley, Minimally invasive treatment of osteoporotic vertebral body compression fractures. Spine J, 2002. 2(1): p. 76-80.

3. Abduljabbar, F.H., A. Al-Jurayyan, S. Alqahtani, Z.M. Sardar, R.S. Saluja, J. Ouellet et al. and P. Jarzem, Does Balloon Kyphoplasty Deliver More Cement Safely into Osteoporotic Vertebrae with Compression 
Fractures Compared with Vertebroplasty? A Study in Vertebral Analogues. Global Spine J, 2015. 5(4): p. 300-7.

4. He, X., H. Li, Y. Meng, Y. Huang, D.J. Hao, Q. Wu, and J. Liu, Percutaneous Kyphoplasty Evaluated by Cement Volume and Distribution: An Analysis of Clinical Data. Pain Physician, 2016. 19(7): p. 495506.

5. Wang, F., L.F. Wang, D.C. Miao, Z. Dong, and Y. Shen, Which one is more effective for the treatment of very severe osteoporotic vertebral compression fractures: PVP or PKP? J Pain Res, 2018. 11: p. 262531.

6. Zhang, Y., L. Shi, P. Tang, and L. Zhang, Comparison of the Efficacy Between Two Micro-Operative Therapies of Old Patients With Osteoporotic Vertebral Compression Fracture: A Network MetaAnalysis. J Cell Biochem, 2017. 118(10): p. 3205-12.

7. Chen, X., J. Ren, J. Zhang, S. Li, and Z. Liu, Impact of Cement Placement and Leakage in Osteoporotic Vertebral Compression Fractures Followed by Percutaneous Vertebroplasty. Clin Spine Surg, 2016. 29(7): p. E365-70.

8. Lee, D.G., C.K. Park, C.J. Park, D.C. Lee, and J.H. Hwang, Analysis of Risk Factors Causing New Symptomatic Vertebral Compression Fractures After Percutaneous Vertebroplasty for Painful Osteoporotic Vertebral Compression Fractures: A 4-year Follow-up. J Spinal Disord Tech, 2015. 28(10): p. E578-83.

9. Belkoff, S.M., J.M. Mathis, L.E. Jasper, and H. Deramond, The biomechanics of vertebroplasty. The effect of cement volume on mechanical behavior. Spine (Phila Pa 1976), 2001. 26(14): p. 1537-41.

10. Fu, Z., X. Hu, Y. Wu, and Z. Zhou, Is There a Dose-Response Relationship of Cement Volume With Cement Leakage and Pain Relief After Vertebroplasty? Dose Response, 2016. 14(4): p. 1559325816682867.

11. Wang, H. and W. Jiang, Re: Nieuwenhuijse MJ, Bollen L, van Erkel AR, Dijkstra PD. Optimal intravertebral cement volume in percutaneous vertebroplasty for painful osteoporotic vertebral compression fractures. Spine 2012,37:1747-55. Spine (Phila Pa 1976), 2013. 38(4): p. 372.

12. Lu, Q., S. Gao, and M. Zhou, The effect of bone cement on the curative effect of percutaneous kyphoplasty in the treatment of osteoporotic vertebral compression fracture. Ann Palliat Med, 2021. 10(10): p. 11013-23.

13. He, S., Y. Zhang, N. Lv, S. Wang, Y. Wang, S. Wu et al. and J. Chen, The effect of bone cement distribution on clinical efficacy after percutaneous kyphoplasty for osteoporotic vertebral compression fractures. Medicine (Baltimore), 2019. 98(50): p. e18217.

14. Li, Q., X. Long, Y. Wang, T. Guan, X. Fang, D. Guo et al. and L. Cai, Clinical observation of two bone cement distribution modes after percutaneous vertebroplasty for osteoporotic vertebral compression fractures. BMC Musculoskelet Disord, 2021. 22(1): p. 577.

15. Lv, B., P. Ji, X. Fan, J. Yuan, T. Xu, X. Yao et al. and T. Zou, Clinical Efficacy of Different Bone Cement Distribution Patterns in Percutaneous Kyphoplasty: A Retrospective Study. Pain Physician, 2020. 23(4): p. E409-e16. 
16. Tan, L., B. Wen, Z. Guo, and Z. Chen, The effect of bone cement distribution on the outcome of percutaneous Vertebroplasty: a case cohort study. BMC Musculoskelet Disord, 2020. 21(1): p. 541.

17. Hackbarth, C.B., T.J. Vogl, N. Naguib, M.H. Albrecht, and P.L. von Knebel-Doeberitz, Long-term evaluation of pain reduction after vertebroplasty and kyphoplasty. Acta Radiol Open, 2021. 10(7): p. 20584601211028994.

18. Liebschner, M.A., W.S. Rosenberg, and T.M. Keaveny, Effects of bone cement volume and distribution on vertebral stiffness after vertebroplasty. Spine (Phila Pa 1976), 2001. 26(14): p. 1547-54.

19. Nieuwenhuijse, M.J., L. Bollen, A.R. van Erkel, and P.D. Dijkstra, Optimal intravertebral cement volume in percutaneous vertebroplasty for painful osteoporotic vertebral compression fractures. Spine (Phila Pa 1976), 2012. 37(20): p. 1747-55.

20. Bernick, S. and R. Cailliet, Vertebral end-plate changes with aging of human vertebrae. Spine (Phila Pa 1976), 1982. 7(2): p. 97-102.

21. Farshad-Amacker, N.A., A. Hughes, R.J. Herzog, B. Seifert, and M. Farshad, The intervertebral disc, the endplates and the vertebral bone marrow as a unit in the process of degeneration. Eur Radiol, 2017. 27(6): p. 2507-20.

22. Rodriguez, A.G., C.K. Slichter, F.L. Acosta, A.E. Rodriguez-Soto, A.J. Burghardt, S. Majumdar, and J.C. Lotz, Human disc nucleus properties and vertebral endplate permeability. Spine (Phila Pa 1976), 2011. 36(7): p. 512-20.

23. Chen, W.J., Y.H. Kao, S.C. Yang, S.W. Yu, Y.K. Tu, and K.C. Chung, Impact of cement leakage into disks on the development of adjacent vertebral compression fractures. J Spinal Disord Tech, 2010. 23(1): p. 35-9.

24. Jamjoom, B., S. Patel, R. Bommireddy, and Z. Klezl, Impact of the quantity of intradiscal cement leak on the progression of intervertebral disc degeneration. Ann R Coll Surg Engl, 2017. 99(7): p. 529-33.

25. Beauséjour, M.H., Y. Petit, J. Hagen, P.J. Arnoux, J.M. Thiong, and E. Wagnac, Contribution of injured posterior ligamentous complex and intervertebral disc on post-traumatic instability at the cervical spine. Comput Methods Biomech Biomed Engin, 2020. 23(12): p. 832-43.

26. Lazáry, A., G. Speer, P.P. Varga, B. Balla, K. Bácsi, J.P. Kósa et al. and P. Lakatos, Effect of vertebroplasty filler materials on viability and gene expression of human nucleus pulposus cells. J Orthop Res, 2008. 26(5): p. 601-7.

27. Sonmez, E., C. Yilmaz, and H. Caner, Development of lumbar disc herniation following percutaneous vertebroplasty. Spine (Phila Pa 1976), 2010. 35(3): p. E93-5.

28. Mirovsky, Y., Y. Anekstein, E. Shalmon, A. Blankstein, and A. Peer, Intradiscal cement leak following percutaneous vertebroplasty. Spine (Phila Pa 1976), 2006. 31(10): p. 1120-4.

29. Wu, J., Y.H. Guan, and S.L. Fan, [Risk factors of non-surgical vertebral fracture after percutaneous kyphoplasty of single segment thoracolumbar fracture]. Zhongguo Gu Shang, 2017. 30(9): p. 833-37.

\section{Figures}



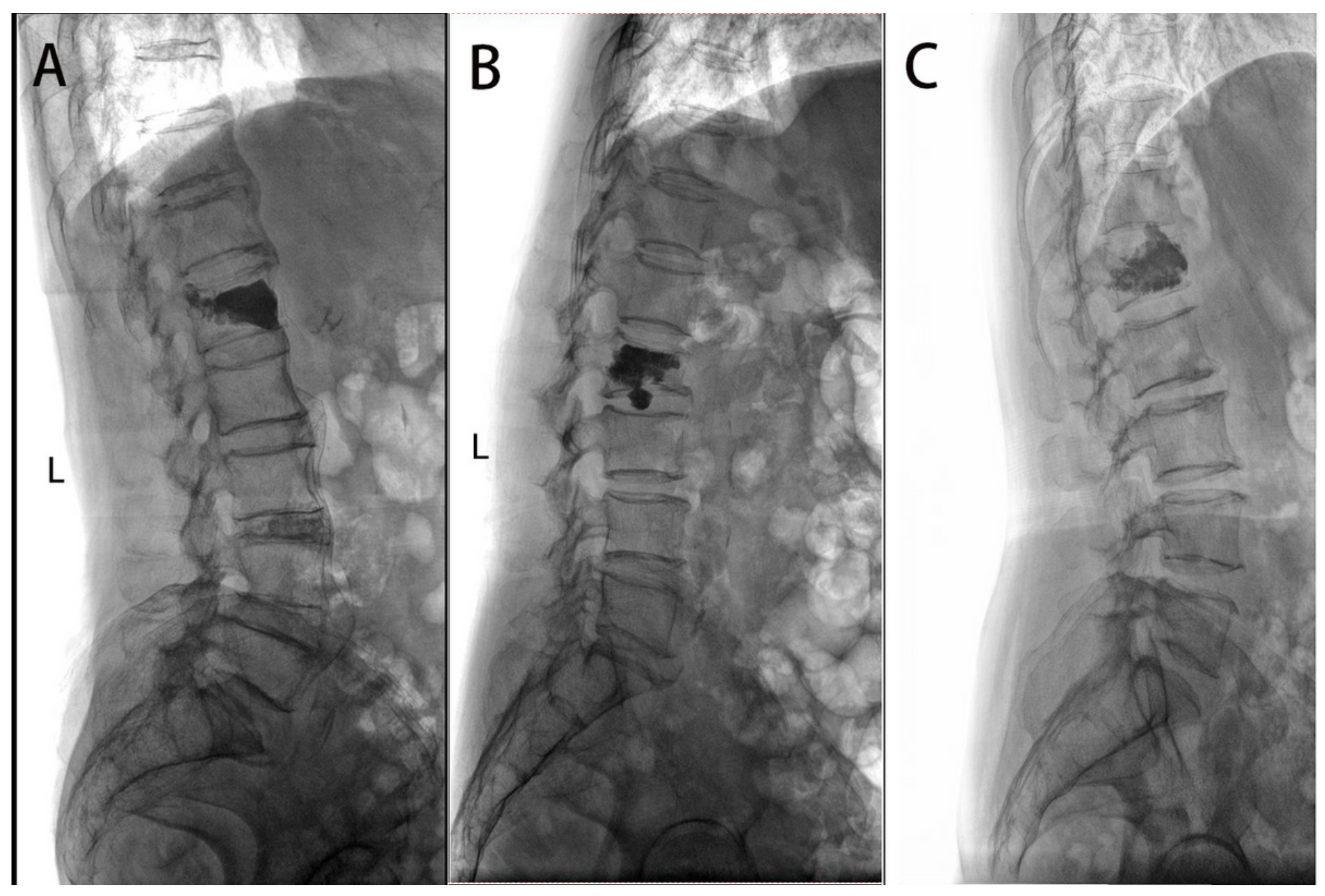

\section{Figure 1}

The three types of bone cement leakage after PKP. 

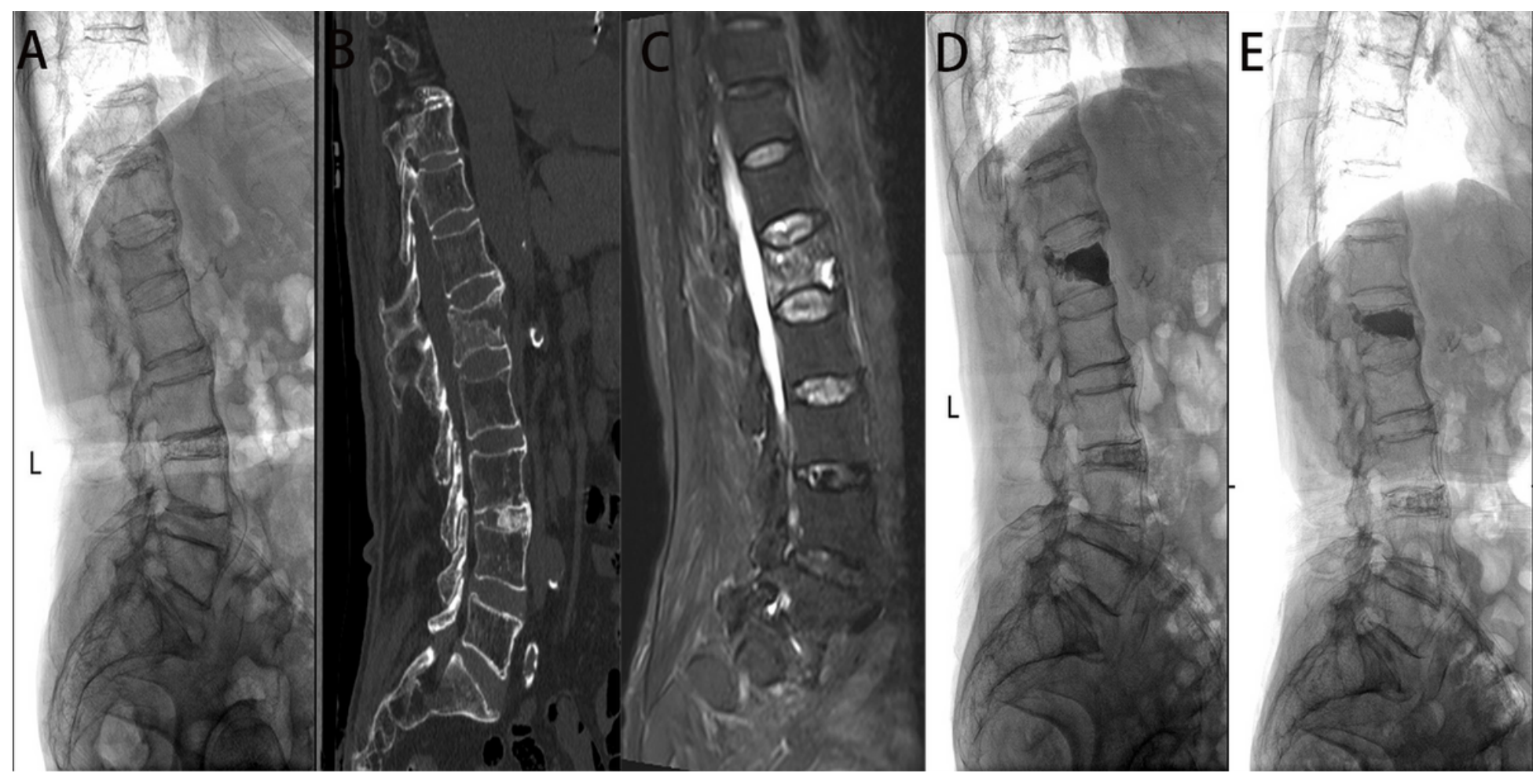

\section{Figure 2}

A 63-year-old female diagnosed as L1 OVCF with Group A shaped cement fifilling pattern. Preoperative Xray from sagittal plane (A), CT (B), MRI (C) and postoperative X-ray from sagittal plane (D) one day after the surgery and $(E)$ at the last follow-up.
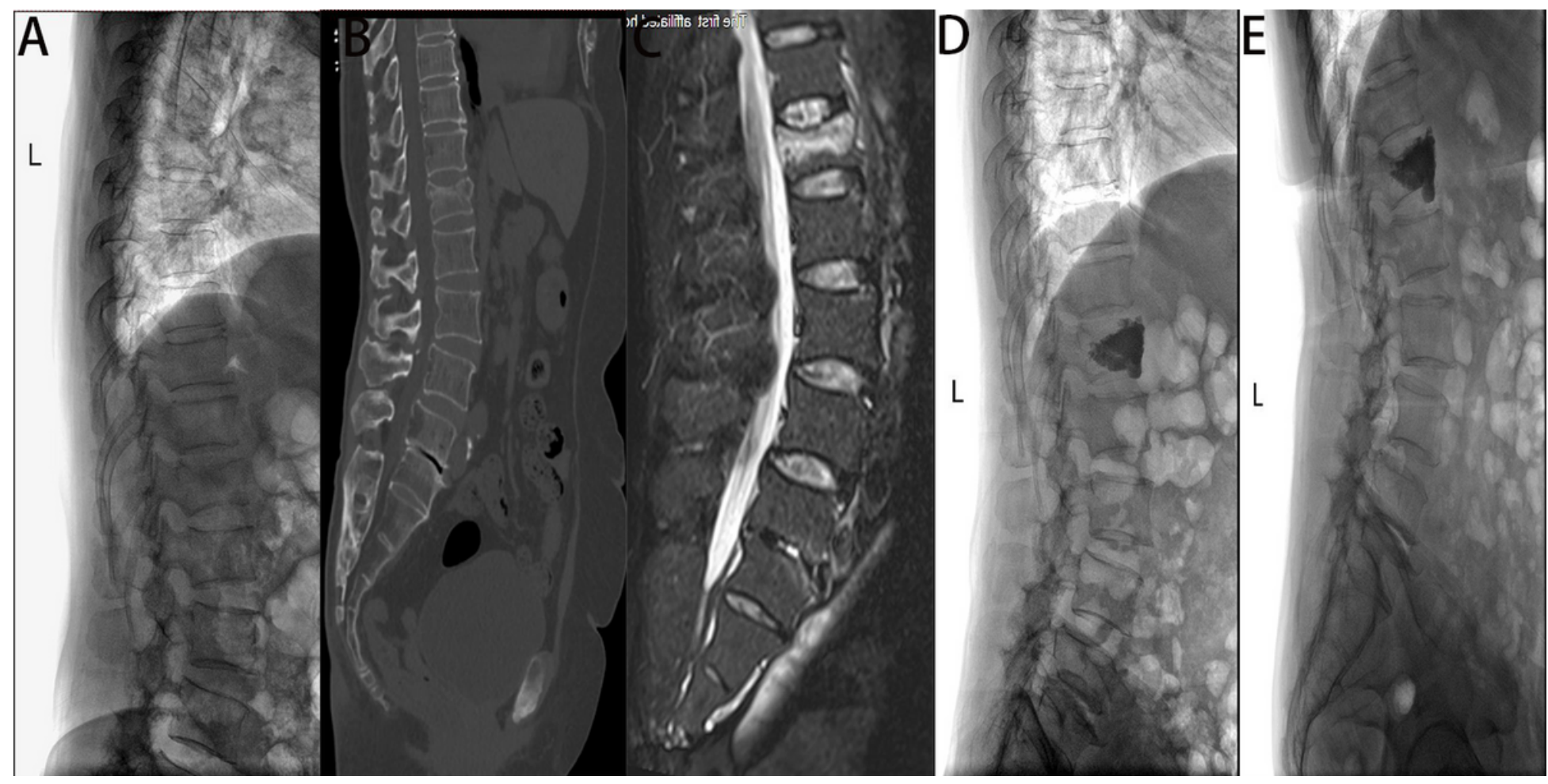

Figure 3 
A 57-year-old female diagnosed as T12 OVCF with Group B shaped cement fifilling pattern. Preoperative X-ray from sagittal plane (A), CT (B), MRI (C) and postoperative X-ray from sagittal plane (D) one day after the surgery and (E) at the last follow-up.
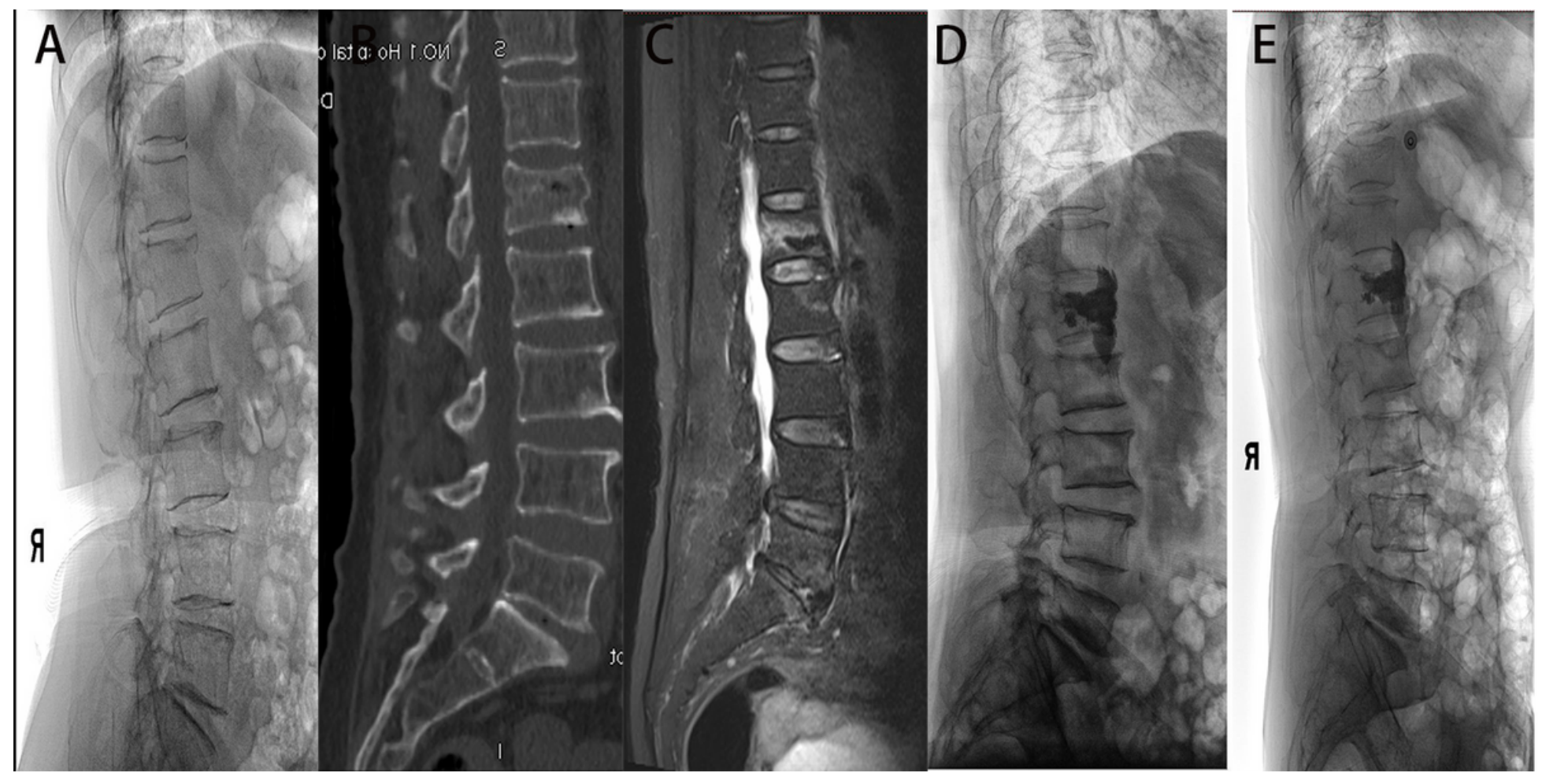

\section{Figure 4}

A 71-year-old female diagnosed as L1 OVCF with Group C shaped cement fifilling pattern. Preoperative Xray from sagittal plane (A), CT (B), MRI (C) and postoperative X-ray from sagittal plane (D) one day after the surgery and $(\mathrm{E})$ at the last follow-up. 


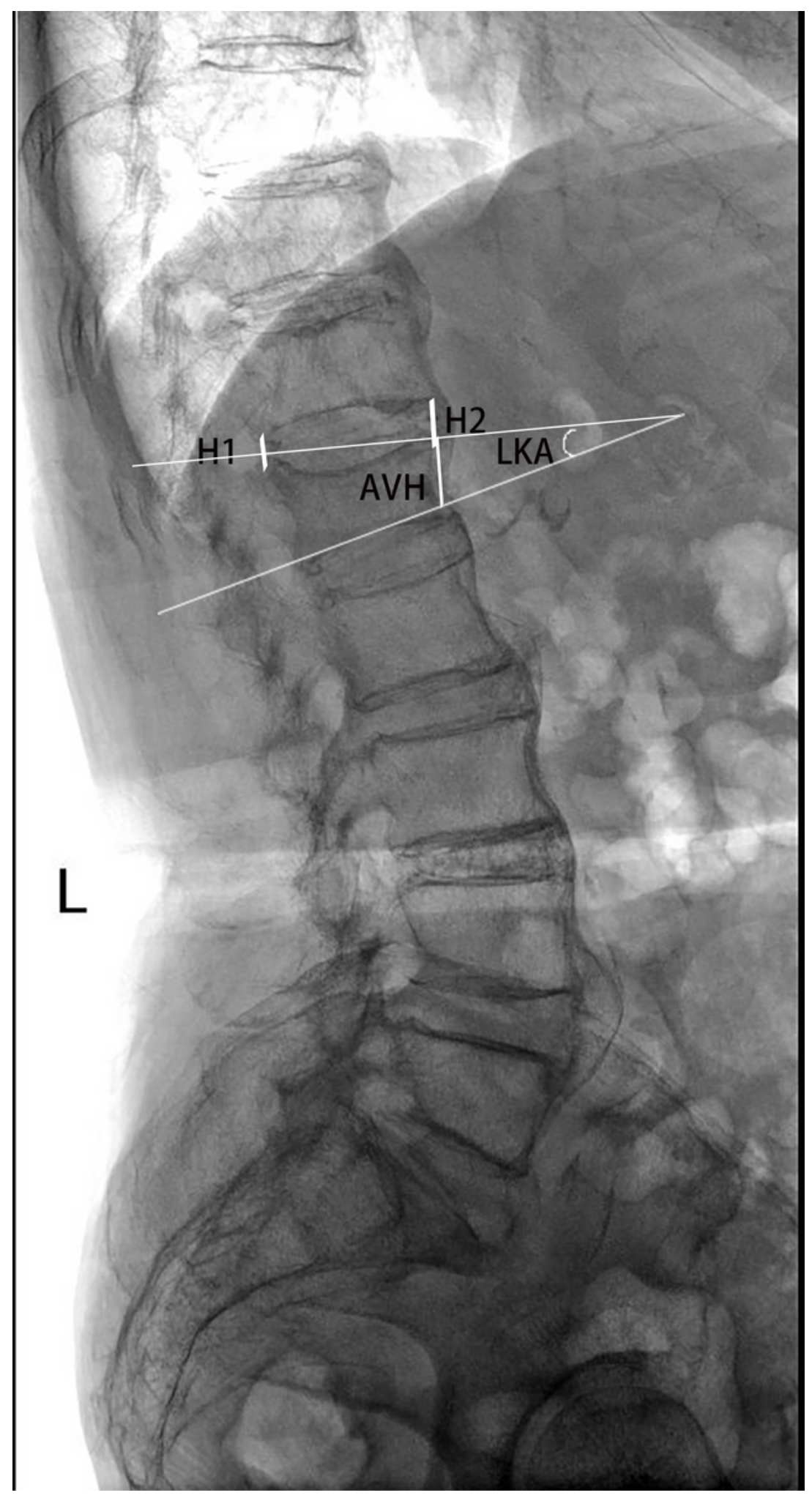

Figure 5

Methods of the surgical parameters. 